\title{
Measuring bladder strength: Letter
}

\author{
Christopher S. Elliott, MD, PhD; Craig V. Comiter, MD
}

Department of Urology, Stanford University School of Medicine, Stanford, CA

Cite as: Can Urol Assoc J 2013;7:18. htrp://dx.doi.org/10.5489/cuai.231

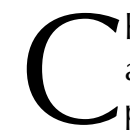
hung and colleagues tackle the important issue of assessing bladder strength in men with voiding complaints after radical prostatectomy. ${ }^{1}$ We agree with the authors that bladder strength has implications for the treatment of post-prostatectomy stress incontinence, because putting a compressive sling in a man with detrusor underactivity could lead to urinary retention. However, we question whether the criteria they used to identify detrusor underactivity is appropriate in men after radical prostatectomy.

The authors report that $41 \%$ of the 264 men who underwent urodynamic study had detrusor underactivity, which they defined as a maximum flow rate (Qmax) less than $15 \mathrm{~mL} / \mathrm{sec}$ and a detrusor pressure at maximum flow (PdetQmax) less than $20 \mathrm{cmH} 2 \mathrm{O}$ during voiding. These criteria are a derivation of the Bladder Contractility Index (BCI) $\left(5^{*} \mathrm{Qmax}+\mathrm{PdetQmax}\right.$, where an index less than 100 is considered weak). Both the $\mathrm{BCl}$ and its derivations have been used in most other studies of bladder strength in men following radical prostatectomy.

However, the $\mathrm{BCl}$ was developed for men with benign prostatic hyperplasia. ${ }^{2}$ Its use in men after the prostate is removed has not been validated. In fact, for women (who have no prostate and may more closely mirror the postprostatectomy population in terms of voiding dynamics) the $\mathrm{BCl}$ and basic pressure flow tests are considered inaccurate for measuring bladder strength. ${ }^{3}$ Similarly, in men who lack normal prostatic resistance, the contractile pressure required to maintain axial flow can approach zero.

The results published by Han and colleagues similarly illustrate the potential inappropriateness of using $\mathrm{BCl}$ determined bladder strength to guide treatment of postprostatectomy stress incontinence. ${ }^{4}$ They reported that in 50 men with weak bladder strength (as measured with the $\mathrm{BCl}$ ), there was no increase in urinary retention after the placement of male slings. They further showed that a man's use of Valsalva to aid in voiding did not predict urinary retention either.

Perhaps, we need to focus on identifying more suitable measures of bladder strength (i.e., Watts factor, isometric detrusor pressure) in this population if we are to improve our understanding of post-prostatectomy voiding dynamics and identify true risk factors for urinary retention after male sling placement. Only then will we be able to appropriately counsel patients on their options for stress incontinence treatment.

\section{References}

1. Chung DE, Dillon B, Kurta J, et al. Detrusor underactivity is prevalent after radical prostatectomy: a urodynamic study including risk factors. Can Urol Assoc J 2013;7:E33-37. Epub 2012 Jan 24. http:// dx.doi.org/10.5489/cuaj.11038

2. Abrams P. Bladder outlet obstruction index, bladder contractility index and bladder voiding efficiency: three simple indices to define bladder voiding function. BJU Int 1999;84:14. http://dx.doi.org/10.1046/ i.1464-410x.1999.00121.x

3. Tan TL, Bergmann MA, Griffiths D, et al. Stop test or pressure-flow study? Measuring detrusor contractility in older females. Neurourol Urodyn 2004;23:184. http://dx.doi.org/10.1002/nau.20020

4. Han JS, Brucker BM, Demirtas A, et al. Treatment of post-prostatectomy incontinence with male slings in patients with impaired detrusor contractility on urodynamics and/or who perform Valsalva voiding. J Urol 2011;186:1370. http://dx.doi.org/10.1016/i.juro.2011.05.089

Correspondence: Dr. Christopher S. Elliott, Department of Urology, Stanford University School of Medicine, Stanford, CA; chrsuz@aol.com

\section{Measuring bladder strength: Author response}

\author{
Jaspreet S. Sandhu, MD
}

Department of Surgery/Urology Service, Memorial Sloan-Kettering Cancer Center, New York, NY

Cite as: Can Urol Assoc J 2013;7:18-9. http://dx.doi.org/10.5489/cuaj.232

W e used a derivation of the Bladder Contractility Index $(\mathrm{BCl})^{1}$ as a measure of bladder strength due to the availability of all variables in our patient population and as a way of identifying potential risk factors. Interestingly, we found that patients who underwent minimally invasive surgery had a higher risk of detrusor underactivity, consistent with current understanding pelvic neural innervation to the bladder and technical differences between minimally invasive surgery and open surgery.

The applicability of these findings to future anti-incontinence procedures remains unclear. Han and colleagues reported no difference with respect to postvoid residual volume or surgical success in patients who underwent a male sling with normal bladder contractility versus those that had 